\title{
UINTA GROUND SQUIRREL DEMOGRAPHY: IS BODY MASS A BETTER CATEGORICAL VARIABLE THAN AGE? ${ }^{1}$
}

\author{
John R. SAUeR ${ }^{2}$ AND Norman A. SLAde \\ Museum of Natural History, and Department of Systematics and Ecology, \\ The University of Kansas, Lawrence, Kansas 66045 USA
}

\begin{abstract}
We compared the relative impact of age and body mass on fecundity and survival in a population of Uinta ground squirrels, and modeled the population using bodymass classes as stage categories in Lefkovitch stage transition matrices. Body mass was a better predictor of survival than was age, and was nearly as good a predictor of litter size. Mass-based stage transition matrices provided results similar to age-based transition matrices, but also indicated that larger and subsequently more fecund young were a consequence of a population reduction. We believe that mass-based analysis of ground squirrel populations is a viable alternative to traditional age-based analyses. Body mass is easy to measure in small-mammal populations and is linked to a variety of life-history characteristics.
\end{abstract}

Key words: body mass; demography; ground squirrels; population ecology; Spermophilus.

\section{INTRODUCTION}

The method for analysis of population dynamics in organisms with life histories that are grouped in discernible stages proposed by Lefkovitch (1965) for use in insects has been successfully applied to a variety of organisms. Werner and Caswell (1977) used this stagebased method to analyze the population dynamics and life history of teasel (Dipsacus sylvestris), and found that size-based stages provided more demographic information than age-based stages. Kirkpatrick (1984) has recently re-emphasized the importance of body size in population dynamics of both plants and animals through a theoretical analysis of continuous-time demographic models. In a series of papers, we have documented variation in somatic growth rates (Slade et al. 1984, Sauer and Slade 1986a) and have used bodymass classes as stage categories in Lefkovitch transition matrices to gain insights into the dynamics of a cotton rat (Sigmodon hispidus) and a prairie vole (Microtus ochrogaster) population near Lawrence, Kansas (Sauer and Slade 1985, 1986b). These temperate rodents, with their short life-spans and fecundity that varies with body mass of the mother, were particularly good candidates for this type of analysis. However, we could not compare the relative importance of age and body mass in affecting fecundity and survival because the study animals could not be accurately aged.

Slade and Balph (1974) constructed traditional life tables for female Uinta ground squirrels (Spermophilus armatus) near Logan, Utah. Because both age and body mass are known for most of these squirrels, compari-

\footnotetext{
${ }^{1}$ Manuscript received 22 July 1985; revised 10 July 1986; accepted 5 August 1986.

${ }^{2}$ Present address: Office of Migratory Bird Management, United States Fish and Wildlife Service, Laurel, Maryland 20708 USA.
}

sons of age and mass effects on litter size and survival are possible, and there is evidence that both might be important. Most studies of ground squirrel demography have concentrated on the analysis of age-specific characteristics of individuals. Differences in social behavior among juveniles, yearlings, and adults have been documented in several species of ground squirrels, and can be reflected in the demography (Slade and Balph 1974, Michener and Michener 1977). Even in adult squirrels, age may play a role in dominance interactions and hence in demography (McLean 1984). Also, litter size has been shown to increase with age in two species, although the relationship is apparently curvilinear (Slade and Balph 1974, Sherman and Morton 1984).

Body mass is also potentially important in ground squirrel demography. Body mass correlates with gestation period, age of maturity, and litter size among North American species of ground squirrels (Armitage 1981), but relationships among life-history characters and body mass within species are only beginning to be examined (Michener 1984a, Murie and Boag 1984). Body mass is most often discussed in ground squirrels with regard to timing of immergence into hibernation (Michener 1984b), and body mass can affect squirrel survival. Murie and Boag (1984) found that Columbian ground squirrels (Spermophilus columbianus) with larger fat reserves survived better than lighter animals with smaller fat reserves. This result could be attributed to age as well because heavier (and older) $S$. columbianus build deeper and more complex burrows (Shaw 1926). The timing of dispersal in juveniles may also be cued by body mass (Holekamp 1984). In other rodents, body mass is strongly correlated with litter size and survival (Falconer 1981, Myers and Master 1983), but these effects have not been as well documented within species of ground squirrels. 
In this paper, we re-examine the data of Slade and Balph (1974) using body mass at emergence from hibernation as a categorical variable rather than age. We compare demographic results of mass- and age-based demography and test the relative impact of body mass and age on litter size and survival.

\section{METHODS}

Uinta ground squirrels were trapped between 1964 and $1971,35 \mathrm{~km}$ northeast of Logan, Utah, USA, at the Utall State University Forestry Field Station. The 8.9-ha study area consisted of a lawn area ( $0.9 \mathrm{ha})$ and a shrub-grass and mixed-tree area (8.0 ha). Yearling and adult ground squirrels were captured in live traps and marked with toe-clips and dye upon emergence in spring, and young of the year were either live-trapped or snared on first emergence. Data were collected on location, body mass, and reproductive condition at first capture, and litter sizes at emergence of young were estimated by number of young emerging from the natal burrows. Population density was manipulated by selective removal of $\approx 40 \%$ of the animals (keeping sex and age composition constant) from 1968 to 1971 as part of a study of the interactions between social behavior and population density. Slade and Balph (1974) and Balphi and Stokes (1963) provide more information on the study area, methods, and results of other aspects of this study.

For comparison with Slade and Balph (1974), we analyzed data separately for three habitats within the study area: lawn, nonlawn, and edge. Of these habitats, ground squirrels were most productive on the lawn, and the other areas had lower population densities (Slade and Balph 1974). We further divided each habitat into high-density (1964-1967) and low-density (1968-1971) periods. Because of small sample sizes, we examined the data compositely within each of the six groups, i.e., we did not examine between-year variation in survival and fecundity.

\section{Determination of relative importance of mass and age on litter size and survival}

Litter size.-Body mass at first capture of the year, age in years, area, and population density (high density [1964-1967] or low density [after 1968]) were examined as independent variables in a linear model with litter size as the dependent variable. The year 1968 was not used because litter sizes may have been modified by stresses associated with removals in that year. We first used one-way analysis of variance (ANOVA) models with age and body-mass classes (explained below) as factors to test the null hypothesis that litter size did not vary among age or mass classes. We then attempted to develop an overall linear model incorporating all the factors listed above.

Survival. - Survival is a binary variable (squirrels survived or disappeared), so we used logistic regression with survival as the dependent variable to analyze body mass and age effects on survival. The BMDP stepwise logistic regression program, BMDPLR (Dixon 1983), was used in the analysis, which incorporated the same independent variables as in the litter-size analysis with the addition of sex as a variable because survival could be determined for both sexes.

\section{Mass-based analysis techniques}

We modeled the dynamics of the Uinta ground squirrel population using Lefkovitch stage transition matrices (Lefkovitch 1965) with body-mass classes as stages. The five mass classes used in this analysis were: (1) 0.0 to $80 \mathrm{~g}$, (2) 81 to $120 \mathrm{~g}$, (3) 121 to $210 \mathrm{~g}$, (4) 211 to $270 \mathrm{~g}$, and (5) $>271 \mathrm{~g}$. The first two classes corresponded to light young and heavy young, and most of the animals in the third class were yearlings, but heavier classes did not correlate highly with ages.

To construct transition matrices for female Uinta ground squirrels, several details of their life history must be taken into account. For a more complete account of the life history, see Balph (1984). Uinta ground squirrels emerge from their winter burrows in spring, and mate. Young are born underground after a gestation period of $23 \mathrm{~d}$, and emerge from the natal burrow at $\approx 22 \mathrm{~d}$ of age. Yearling females (animals $1 \mathrm{yr}$ in age) frequently mate and produce young. By mid-August all animals have immerged into their winter burrows. To analyze this life cycle, we separated it into two phases: reproduction (production of young, from mating to emergence of young) and yearly somatic growth and survival. Each of these phases was incorporated into matrix form and then multiplied together to provide the yearly transition matrices. We set up separate transition matrices for each area and population density. Matrix A (which comprises reproduction) is of form:

$$
\left[\begin{array}{ccccc}
f_{11} & f_{12} & f_{13} & f_{14} & f_{15} \\
f_{21} & f_{22} & f_{23} & f_{24} & f_{25} \\
0 & 0 & 1 & 0 & 0 \\
0 & 0 & 0 & 1 & 0 \\
0 & 0 & 0 & 0 & 1
\end{array}\right]
$$

where $f_{i j}$ is the average number of young of mass class $i$ produced by a female in mass class $j$ at time $t$. Matrix B (which comprises the survival and transition probabilities from one mass class to another during a year) is of form:

$$
\left[\begin{array}{ccccc}
0 & 0 & 0 & 0 & 0 \\
0 & 0 & 0 & 0 & 0 \\
P_{31} & P_{32} & P_{33} & P_{34} & P_{35} \\
P_{41} & P_{42} & P_{43} & P_{44} & P_{45} \\
P_{51} & P_{52} & P_{53} & P_{54} & P_{55}
\end{array}\right]
$$

where $P_{i j}$ is the probability that an animal in mass class 

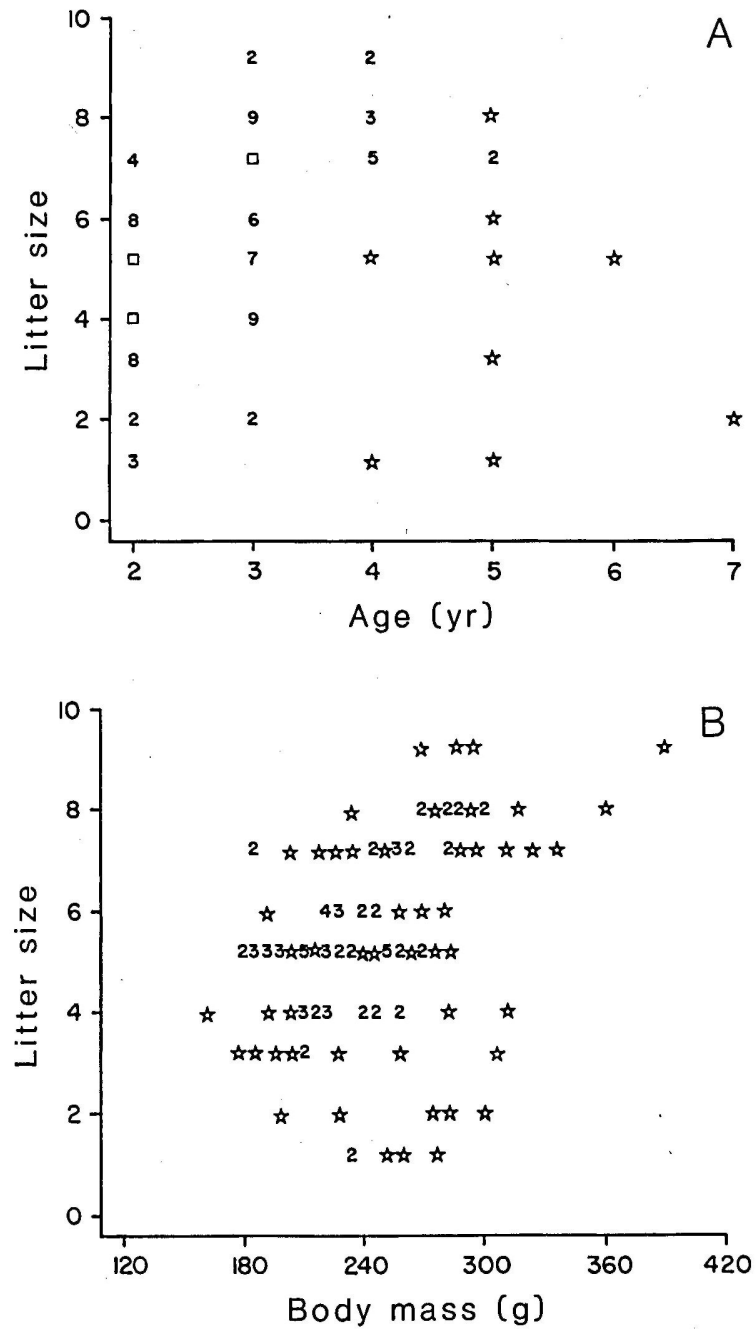

Fig. 1. Scatterplots of litter size vs. age (A) and litter size vs. body mass (B) in female Uinta ground squirrels. A single

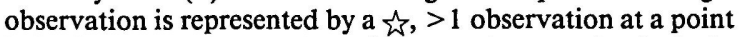
is indicated by the number of observations, and $>9$ observations at a point is indicated by $a \square$.

$j$ on emergence in year $t$ survives and enters mass class $i$ in year $t+1$.

The overall yearly transition matrices are defined by the matrix product $\mathbf{A B}$. This transition matrix represents a set of "rules" by which the observed mass structure of the population at time $t, n_{t}$, is projected to find the number of animals in each mass class at time $t+$ 1, according to the equation:

$$
\mathbf{A B} n_{t}=n_{t+1} .
$$

In our vectors $\left(n_{t}\right)$, the first two elements represent young of the year, and the other elements correspond to heavier animals. No heavier animals ever lost enough mass to re-enter the first two mass classes, so the lightest classes only gain individuals through fecundity of heavier animals.
TABLE 1. Litter sizes by mass class for Uinta ground squirrels before and after $40 \%$ population reduction, with associated standard errors and sample sizes.

\begin{tabular}{|c|c|c|c|c|c|c|}
\hline \multirow{3}{*}{$\begin{array}{l}\text { Mass } \\
\text { class }\end{array}$} & \multicolumn{3}{|c|}{ High density } & \multicolumn{3}{|c|}{ Low density } \\
\hline & \multicolumn{2}{|c|}{ Litter size } & \multirow[b]{2}{*}{$N$} & \multicolumn{2}{|c|}{ Litter size } & \multirow[b]{2}{*}{$N$} \\
\hline & $\overline{\bar{X}}$ & SE & & $\bar{X}$ & SE & \\
\hline $\begin{array}{l}3 \\
4 \\
5\end{array}$ & $\begin{array}{l}4.59 \\
5.25 \\
6.12\end{array}$ & $\begin{array}{l}.252 \\
.241 \\
.331\end{array}$ & $\begin{array}{l}22 \\
52 \\
33\end{array}$ & $\begin{array}{l}4.44 \\
5.16 \\
6.38\end{array}$ & $\begin{array}{l}.475 \\
.318 \\
.738\end{array}$ & $\begin{array}{r}9 \\
19 \\
13\end{array}$ \\
\hline
\end{tabular}

\section{Estimation of elements of the matrices}

Transition probabilities. - The time interval of the transition matrices is $1 \mathrm{yr}$, so the transition probabilities were found by first totalling the number of animals that changed in body mass from mass class $j$ to mass class $i$ between years $\left(c_{i j}\right)$, and those that disappeared from mass class $j\left(d_{j}\right)$. The $P_{i j}$ were then estimated by

$$
P_{i j}=\frac{c_{i j}}{d_{j}+\sum_{k=1}^{5} c_{k j}} .
$$

Body mass of young was measured on emergence from the natal burrow, whereas body mass of adults was measured on first capture after spring emergence.

We also estimated high- and low-density transition probabilities for males, without regard to habitat, for comparison with those of females.

Fecundity elements. - Fecundity of ground squirrels in a mass class was estimated as a product of the proportion of reproductive females in the mass class, the mean litter sizes in the mass class, and the sex ratio of young in the mass class. Sex ratio and litter size were determined at emergence of young from the burrows, so pre-emergence losses are taken into account. Uinta ground squirrels breed after emergence from their winter burrows. As the young are not conceived until after the end of winter, overwinter mortality of females need not be considered in the fecundity elements of the transition matrices.

Evidence exists that body mass of young can affect winter survival (Murie and Boag 1984), so we divided young into light $(<80 \mathrm{~g})$ and heavy $(81-120 \mathrm{~g})$ categories based on body mass at emergence. The proportion of young in these two mass classes was found for each adult mass class, and the fecundity of the adult mass classes was further multiplied by these proportions.

TABLE 2. Independent variables from the logistic regression on survival of Uinta ground squirrels, with associated coefficients and standard errors.

\begin{tabular}{lcc}
\hline \hline Variable & Coefficient & SE \\
\hline Body mass & .0032 & .0005 \\
Sex & .1510 & .0433 \\
Density & .1730 & .0588 \\
Constant & .9630 & .1050 \\
\hline
\end{tabular}


TABle 3. Proportion $(P)$ of female Uinta ground squirrels that were reproductive at high and low densities by age and mass class.

\begin{tabular}{|c|c|c|c|c|}
\hline & \multicolumn{2}{|c|}{ High density } & \multicolumn{2}{|c|}{ Low density } \\
\hline & $P$ & $N$ & $P$ & $N$ \\
\hline \multicolumn{5}{|c|}{ Mass class } \\
\hline $\begin{array}{l}3 \\
4 \\
5\end{array}$ & $\begin{array}{l}0.6283 \\
0.6503 \\
0.8022\end{array}$ & $\begin{array}{r}113 \\
203 \\
91\end{array}$ & $\begin{array}{l}0.7500 \\
0.7609 \\
0.7391\end{array}$ & $\begin{array}{l}20 \\
46 \\
23\end{array}$ \\
\hline \multicolumn{5}{|c|}{ Age class } \\
\hline $\begin{array}{l}1 \\
2 \\
3 \\
4 \\
5 \\
6\end{array}$ & $\begin{array}{c}0.6388 \\
0.7273 \\
0.6316 \\
0.6000 \\
0.0000 \\
\ldots\end{array}$ & $\begin{array}{r}227 \\
77 \\
19 \\
5 \\
1 \\
\ldots\end{array}$ & $\begin{array}{l}0.7297 \\
0.8800 \\
0.7857 \\
0.7143 \\
0.6667 \\
1.0000\end{array}$ & $\begin{array}{r}37 \\
25 \\
14 \\
7 \\
3 \\
1\end{array}$ \\
\hline
\end{tabular}

For comparison with the mass-based transition matrices, we constructed Leslie matrices (Leslie 1945) for female ground squirrels in each habitat and density. Age-based estimates of male survival at high and low density were also estimated for all habitats combined.

\section{Analysis of transition matrices}

Once these transition matrices were estimated, analysis of their structure provided much information on the population. The dominant eigenvalue $(\lambda)$ of the matrix represents the finite rate of increase of a population, in a stable mass distribution, that grows (or declines) according to the vital statistics of the matrix. The stable mass distribution of the population is represented by the right eigenvector $(u)$ and the vector of reproductive values of the mass classes by the left eigenvector $(y)$ corresponding to the dominant eigenvalue (Werner and Caswell 1977). Both the vector of stable mass distributions and the vector of reproductive values can provide considerable information on the relative importance of each mass class. In addition, Caswell (1978) has described a technique for examining the relative sensitivity of population growth rates to changes in elements of the transition matrices. The sensitivity of $\lambda$ to a change in element $m_{i j}$ of the transition matrix is:

$$
\frac{d \lambda}{d m_{i j}}=\frac{u_{i} v_{j}}{u^{\prime} v}
$$

where $v_{j}, u_{i}$ represent elements of the eigenvectors and $u^{\prime} v$ is the inner product of the eigenvectors. These sensitivities show how changing an element of the transition matrix changes population growth, and hence how sensitive population growth rate is to changes in growth, survival, and fecundity of the different mass classes.

\section{RESUlTS}

\section{Correlation of body mass and age}

Body mass correlated well with age in female Uinta ground squirrels $(r=0.832, N=1285, P=.0001)$.
This correlation was due in large part to the influence of lighter animals, because when these lst-yr animals were removed from the analysis the relationship between body mass and age was not as strong $(r=0.544$, $N=492, P=.0001)$. Removing yearlings from the analysis further weakened the correlation $(r=0.105$, $N=191, P>.05$ ). Hence, after the animals reached their 2 nd yr, body mass was not greatly affected by the age of the animal. An analysis of variance using ages of adult animals as factors found no effect of age on adult body mass $(F=1.53$, df $=4,186, P>.1)$. This poor relationship between age and body mass in adults is apparently common in rodents (Sauer and Slade 1985).

\section{Age and body-mass effects on litter size}

Both age and body mass were correlated with litter size (Fig. 1). One-way ANOVA indicated unequal mean litter sizes for body mass $(F=10.11, \mathrm{df}=2,127, P<$ $.001)$ and age class $(F=8.54, \mathrm{df}=4,125, P<.001)$. The strength of the relationship was similar for both groups, using the MSE as a measure of "closeness of fit" for the analyses (1.676 for age, 1.744 for body mass). Mean litter size increased with body mass for both high and low population densities (Table 1), but we found no relationship between litter size and population density or habitat type (all $P>.1$ ). As discussed by Slade and Balph (1974), litter size appears to have a nonlinear relationship with age, and maximal litter sizes occur in intermediate ages. Three-year-old squirrels had a mean litter size of 6.9 , while squirrels aged 5 yr or more had a mean litter size of 3.5.

\section{Age and body-mass effects on survival}

Body mass, sex, and density were all significantly related to survival (Table 2), and the three-variable model fits the data $\left(\chi^{2}=11.417\right.$, df $\left.=7, P<.121\right)$. Annual survival increased with body mass; hence, light animals did not survive as well as heavy animals. Age effects were not as strong as mass effects and did not explain any additional variation in survival after body

TABLE 4. Sex ratios (proportions of females) in litters of Uinta ground squirrels at high and low densities by age and mass class.

\begin{tabular}{cccccc}
\hline \hline & \multicolumn{2}{c}{ High density } & & \multicolumn{2}{c}{ Low density } \\
\cline { 2 - 3 } \cline { 5 - 6 } \multicolumn{2}{c}{ Sex ratio } & $N$ & & Sex ratio & $N$ \\
\hline \multicolumn{2}{c}{ Mass class } & & & & \\
3 & 0.5484 & 155 & & 0.2500 & 28 \\
4 & 0.5113 & 354 & & 0.4444 & 72 \\
5 & 0.5000 & 36 & & 0.6182 & 55 \\
Age class & & & & & \\
1 & 0.5488 & 328 & & 0.4200 & 50 \\
2 & 0.5049 & 204 & & 0.5522 & 67 \\
3 & 0.5000 & 58 & & 0.5417 & 24 \\
4 & 0.5625 & 16 & & 0.4167 & 12 \\
5 & $\cdots$ & $\cdots$ & & 0.6667 & 6 \\
6 & $\cdots$ & $\cdots$ & & 1.0000 & 1 \\
\hline
\end{tabular}


TABle 5. (A) Mass-based temporal transition probabilities and (B) age-specific survival rates of female Uinta ground squirrels at high (pre-removal) and low (post-removal) densities.

\begin{tabular}{|c|c|c|c|c|c|c|}
\hline & \multicolumn{3}{|c|}{ High density } & \multicolumn{3}{|c|}{ Low density } \\
\hline \multicolumn{7}{|c|}{ A) Transition probabilities } \\
\hline \multirow{2}{*}{$\begin{array}{c}\text { Mass } \\
\text { class } \\
\text { at } t\end{array}$} & \multicolumn{3}{|c|}{ Mass class at $t+1$} & \multicolumn{3}{|c|}{ Mass class at $t+1$} \\
\hline & 3 & 4 & 5 & 3 & 4 & 5 \\
\hline $\begin{array}{l}1 \\
2 \\
3 \\
4 \\
5\end{array}$ & $\begin{array}{l}.114 \\
.133 \\
.101 \\
.005 \\
.000\end{array}$ & $\begin{array}{l}.114 \\
.178 \\
.250 \\
.206 \\
.139\end{array}$ & $\begin{array}{l}.026 \\
.037 \\
.058 \\
.231 \\
.302\end{array}$ & $\begin{array}{l}.313 \\
.188 \\
.138 \\
.000 \\
.000\end{array}$ & $\begin{array}{l}.125 \\
.271 \\
.172 \\
.333 \\
.231\end{array}$ & $\begin{array}{l}.000 \\
.000 \\
.035 \\
.191 \\
.346\end{array}$ \\
\hline
\end{tabular}

B) Survival rates (from time $t$ to time $t+1$ )

\begin{tabular}{ccc}
$\begin{array}{c}\text { Age } \\
\text { at } t\end{array}$ & \\
\hline 0 & .3380 & .4125 \\
1 & .4554 & .5000 \\
2 & .3784 & .5313 \\
3 & .5263 & .5833 \\
4 & .2500 & .7500 \\
\hline
\end{tabular}

mass was entered into the logistic regression model. Survival also increased after removals were started, and males did not survive as well as females.

\section{Proportion of reproductive females}

Proportions of females that successfully reproduced varied between 0.4118 (edge, high density) and 0.9062 (lawn, high density). Significant associations existed between proportion of reproductive females and density, habitat type, and mass class (loglinear model, $\chi^{2}=$ 26.82 , df $=22, P=.22$ ). With a few exceptions such as edge, low density, the proportions of reproductive females decreased as habitat changed from lawn to nonlawn to edge. Overall, in mass classes 3 and 4 the proportion of reproductive females increased after removals were started (post-1968), but in mass class 5 a decrease occurred (Table 3 ). In the age-specific analysis, similar patterns of decrease occurred as habitats changed from lawn to nonlawn to edge, and of increase as densities were lowered (Table 3).

\section{Sex ratios}

The sex ratio of emerging squirrels did not vary among habitats, but was related to the mother's body mass (Table 4). Lighter animals produced significantly fewer females at low density $(z=2.91, P<.01)$; this was reflected in a weaker pattern of fewer females being produced by yearlings at low density $(z=1.7, P<$ $.09)$.

\section{Transition probabilities of female Uinta ground squirrels}

Mass-based. - These transition probabilities represent the probability of surviving and moving from one mass class to another in the course of a year (Table 5). Except in mass class 3, the probability of survival (found by summing within each row) increased at lower population density. However, since mortality was confounded with dispersal in these estimates, this increased survival may represent decreased dispersal. Mass classes 1 and 2 did not show consistent patterns of variation in survival, although it is of interest to note that squirrels in mass class 2 always had a higher probability of entering mass classes 4 and 5 than did animals in mass class 1 .

Age-based. - At high density, female squirrels survived best in intermediate ages (ages $1,2,3$ ). At low density, survival increased with age. Perhaps a major effect of removing animals was to differentially increase survival of older animals.

\section{Transition probabilities of male Uinta ground squirrels}

As in female ground squirrels, mass-based transition probabilities for males increased in all but one mass class (mass class 4 ) after removals were started (Table 6). Except for mass class 3, low density, females survived better than males.

Due to small sample sizes, age-based survival rates were combined for males $\geq 2 \mathrm{yr}$ of age (Table 6). In juvenile and yearling males, survival increased after removals were started; in older animals survival decreased after removals. At high densities, survival of juvenile and yearling males was less than that of females; after removals were started these males had greater survival rates than did females of the same ages. Older males survived better than females (survival rate for females $\geq 2$ yr of age was 0.4021 ) at high density, but low-density older females (survival rate was 0.5625 ) survived better than males.

\section{Analysis of transition matrices}

Transition matrices. - Using the transition probabilities and fecundities, we constructed transition ma-

TABLE 6. Transition probabilities based on body mass classes and survival probabilities by age for male Uinta ground squirrels at high (pre-removal) and low (post-removal) densities.

\begin{tabular}{|c|c|c|c|c|c|c|}
\hline & \multicolumn{3}{|c|}{ High density } & \multicolumn{3}{|c|}{ Low density } \\
\hline \multicolumn{7}{|c|}{ A) Transition probabilities } \\
\hline \multirow{2}{*}{$\begin{array}{c}\text { Mass } \\
\text { class } \\
\text { at } t\end{array}$} & \multicolumn{3}{|c|}{ Mass class at $t+1$} & \multicolumn{3}{|c|}{ Mass class at $t+1$} \\
\hline & 3 & 4 & 5 & 3 & 4 & 5 \\
\hline $\begin{array}{l}1 \\
2 \\
3 \\
4 \\
5\end{array}$ & $\begin{array}{l}.050 \\
.025 \\
.024 \\
.000 \\
.000\end{array}$ & $\begin{array}{l}.092 \\
.123 \\
.102 \\
.020 \\
.000\end{array}$ & $\begin{array}{l}.021 \\
.055 \\
.134 \\
.373 \\
.367\end{array}$ & $\begin{array}{l}.053 \\
.061 \\
.065 \\
.000 \\
.000\end{array}$ & $\begin{array}{l}.263 \\
.306 \\
.323 \\
.000 \\
.039\end{array}$ & $\begin{array}{l}.053 \\
.041 \\
.097 \\
.313 \\
.346\end{array}$ \\
\hline \multicolumn{6}{|c|}{ B) Survival rates (from time $t$ to time $t+1$ ) } & $\begin{array}{l}\text { Age } \\
\text { at } t\end{array}$ \\
\hline $\begin{array}{r}0 \\
1 \\
\geq 2\end{array}$ & & $\begin{array}{l}.264 \\
.414 \\
.446\end{array}$ & & & $\begin{array}{l}.436 \\
.522 \\
.353\end{array}$ & \\
\hline
\end{tabular}


TABLE 7. Population growth rates (dominant eigenvalues of the transition matrices) of Uinta ground squirrels by area and high vs. low density. Slade and Balph (1974) used average adult fecundity and survival rates.

\begin{tabular}{|c|c|c|c|c|c|c|c|c|}
\hline \multirow[b]{2}{*}{ Source } & \multicolumn{2}{|c|}{ Lawn } & \multicolumn{2}{|c|}{ Nonlawn } & \multicolumn{2}{|c|}{ Edge } & \multicolumn{2}{|c|}{ Overall } \\
\hline & High & Low & High & Low & High & Low & High & Low \\
\hline $\begin{array}{l}\text { Slade and Balph (1974) } \\
\text { Mass } \\
\text { Age }\end{array}$ & $\begin{array}{l}1.05 \\
0.99 \\
1.06\end{array}$ & $\begin{array}{l}1.33 \\
1.07 \\
1.20\end{array}$ & $\begin{array}{l}0.94 \\
1.01 \\
0.95\end{array}$ & $\begin{array}{l}1.46 \\
1.72 \\
1.57\end{array}$ & $\begin{array}{l}0.96 \\
0.80 \\
1.03\end{array}$ & $\begin{array}{l}0.97 \\
\cdots \\
\cdots\end{array}$ & $\begin{array}{l}0.96 \\
0.97 \\
1.05\end{array}$ & $\begin{array}{l}1.36 \\
1.17 \\
1.30\end{array}$ \\
\hline
\end{tabular}

trices for each area and density using the body-mass categories. Criteria for stability of these matrices are discussed in Lefkovitch (1965); all of these matrices meet the criteria. Age-based Leslie matrices were also estimated from survival and fecundity data. High- and low-density lawn and overall matrices were of dimension $6 \times 6$, but other matrices were $5 \times 5$ in dimension. Insufficient data existed for the estimation of massbased transition matrices for low-density edge animals, so we did not include those animals in the analysis.

Population growth rates. - The dominant eigenvalues of the transition matrices (Table 7) varied with habitat and density. There was no consistent pattern of differences between age- and mass-based estimates. The age-based estimates varied slightly from those estimated by Slade and Balph (1974), who used mean estimates of fecundity and survival for adult females to construct their life tables. Mass-based estimates showed the same pattern of increase after removals began, but some of the estimates varied in magnitude. Some of these differences were explicable through examination of the transition matrices: in low-density nonlawn habitat estimates, for example, the large eigenvalue (1.72) was primarily due to a small sample size of light (mass class 1) young, biasing the estimate of young survival.

Stable stage distributions. - Little difference existed between high- and low-density stable mass distribu- tions in the Uinta ground squirrels. Most of the ground squirrels were in mass classes 1 and 2 . At high densities, more of the young were in mass class 1 , whereas at low densities more of the young were in mass class 2 . Some variation also occurred between habitats within density, but these differences were generally small.

Stable age distributions were also quite similar at high and low densities. Most of the animals were yearlings (age class 1). The proportion of animals in an age class consistently decreased with age, a pattern that did not occur with body mass.

Reproductive values. - Mass-based reproductive rates generally increased with body-mass class. Heavier mass classes became relatively more important at low density. Age-based reproductive values generally reached a maximum in intermediate age classes, reflecting the high survival and litter sizes of these classes. The agebased reproductive values of older squirrels also showed an increase after removals were started.

Sensitivities. - In general, sensitivities of the dominant eigenvalue to changes in transition elements from the mass-based analysis were highest for growth and survival of the lightest mass classes, particularly for transitions of light young (class 1) to heavier mass classes (Table 8). At low densities, the heaviest mass class was less important, while mass class 4 was more important.

Sensitivity analysis of age-based transition matrices showed that yearling reproduction $\left(f_{1}\right)$ and juvenile

TABLE 8. Sensitivities of the population growth rate to changes in elements of overall mass- and age-specific transition matrices for high and low Uinta ground squirrel densities.

\begin{tabular}{|c|c|c|c|c|c|c|c|c|c|c|c|c|}
\hline \multirow{3}{*}{$\begin{array}{l}\text { Class } \\
\text { at time. } \\
t+1\end{array}$} & \multicolumn{6}{|c|}{ High density } & \multicolumn{6}{|c|}{ Low density } \\
\hline & \multicolumn{6}{|c|}{ Class at time $t$} & \multicolumn{6}{|c|}{ Class at time $t$} \\
\hline & 1 & 2 & 3 & 4 & 5 & 6 & 1 & 2 & 3 & 4 & 5 & 6 \\
\hline \multicolumn{13}{|l|}{ Mass } \\
\hline $\begin{array}{l}1 \\
2 \\
3 \\
4 \\
5\end{array}$ & $\begin{array}{l}.275 \\
.379 \\
.452 \\
.535 \\
.550\end{array}$ & $\begin{array}{l}.185 \\
.256 \\
.305 \\
.361 \\
.371\end{array}$ & $\begin{array}{l}.065 \\
.090 \\
.107 \\
.126 \\
.130\end{array}$ & $\begin{array}{l}.117 \\
.162 \\
.193 \\
.229 \\
.235\end{array}$ & $\begin{array}{l}.067 \\
.092 \\
.110 \\
.130 \\
.134\end{array}$ & & $\begin{array}{l}.187 \\
.246 \\
.195 \\
.408 \\
.485\end{array}$ & $\begin{array}{l}.240 \\
.316 \\
.251 \\
.524 \\
.622\end{array}$ & $\begin{array}{l}.101 \\
.132 \\
.105 \\
.219 \\
.261\end{array}$ & $\begin{array}{l}.137 \\
.180 \\
.143 \\
.298 \\
.355\end{array}$ & $\begin{array}{l}.036 \\
.047 \\
.038 \\
.078 \\
.093\end{array}$ & \\
\hline \multicolumn{13}{|l|}{ Age } \\
\hline $\begin{array}{l}1 \\
2 \\
3 \\
4 \\
5 \\
6\end{array}$ & $\begin{array}{l}.581 \\
.864\end{array}$ & $\begin{array}{l}.188 \\
.230\end{array}$ & .082 & .013 & .015 & .004 & $\begin{array}{l}.540 \\
.949\end{array}$ & $\begin{array}{l}.171 \\
.283\end{array}$ & .066 & .027 & .012 & .007 \\
\hline
\end{tabular}


survival were most important in affecting the dominant eigenvalue.

\section{DISCUSSION}

\section{The roles of body mass and age in affecting} fecundity and survival

We selected Uinta ground squirrels for our comparison of mass- and age-based demography because we knew appropriate data existed. However, given the longevity of some squirrels and the demonstrated decrease of litter size in older adults, we were pessimistic as to the efficacy of the mass-based approach. The results were very encouraging; body mass equalled or exceeded age as a predictor of litter size and survival. These relationships between body mass in the spring and annual survival and fecundity have not been previously documented for any species of ground squirrel, and may have profound implications for the study of ground squirrel demography. In addition, mass-based techniques provide all the results of age-based methods plus insights into the dynamics of the population that cannot be examined using age-based methods.

For example, in our study, young of the year were in mass classes 1 and 2 . Two subclasses of this age class in $S$. columbianus were found to have different chances of overwinter survival by Murie and Boag (1984). We too found that heavier mass class 2 female young survived better than did mass class 1 young (Table 5 ). After removals were started, the proportion of mass class 2 females in the stable mass distribution increased and even though the survival difference between the two classes was not as great, larger young were more likely to advance to mass class 4 as yearlings, thus achieving higher fecundity. Removal of animals may increase availability of food or reduce social strife for mothers, allowing them to increase ingestion during pregnancy and hence increase prenatal growth of young. This indicates to us that in ground squirrels, as in many other rodents (Falconer 1981), relationships exist between nutrition of the mother and size of the young. Changes in the sex ratios of the litters may also influence this, as heavier mothers produce heavier young, and more of the female young after removals were produced by heavy females.

Young female ground squirrels are quite variable in growth rate, and can enter any of the "adult" mass classes (mass classes 3,4 , or 5 ) by the time they are yearlings. This means that mass class 3 is actually composed of several age groups, including yearlings and 2-yr-old animals, and cannot be treated as a yearling mass class. However, these "light adults" generally tend to remain light, and after removals their growth rates actually seem to decrease (Table 5).

Age effects on survival and fecundity are important in young and very old Uinta ground squirrels. Female Uinta ground squirrels can live $>7 \mathrm{yr}$ in nature, and experience changes in litter size related to old age. Sher- man and Morton (1984) found that female Belding's ground squirrels ( $S$. beldingi) showed similar old-age changes. They also found that, whereas dispersal of younger males was a significant factor in male population dynamics, female dispersal was less important as female young tended to remain near their mother's burrow. This sexual difference in dispersal also occurs in Uinta ground squirrels (Slade and Balph 1974).

\section{Changes associated with the removal of animals}

Slade and Balph (1974) found that, after population reduction, population growth increased because of increases in both the percentage of yearlings breeding and in the number of juveniles remaining on the study area. Both the age- and mass-based analyses presented here also indicate that the population growth rate increased after removals began. Changes occurred in the mass-based analysis at low density that correspond to changes observed by Slade and Balph (1974) for the age-based analysis. The increase in juveniles remaining on the study site is analogous to the increase in survival rates of animals in mass classes 1 and 2. In mass classes 3 and 4 an increase in the proportion of reproductive females occurred at low density, so more light adults were breeding. Further changes occurred in the stable mass analysis after the population reduction. Before reduction, more light than heavy young were predicted, but after reduction heavier young were predicted to be more abundant. This prediction has demographic significance, as heavy young are more likely to move to heavier mass classes within a year. However, the prediction could not have been made using age-based demography.

\section{Sensitivity analysis and ground squirrel growth}

Many investigators have studied somatic growth rates of juvenile ground squirrels (e.g., Clark 1970), and it has been suggested that growth in species that hibernate is greater than juvenile growth in nonhibernating species (e.g., Neal 1965, Clark 1970). Although this view has been questioned, and insufficient data exist to make valid interspecies comparisons (Levenson 1979), growth of young ground squirrels has been shown to play a role in their survival (Murie and Boag 1984). Many factors, including size of litter and nutritional state of the mother, can potentially interact to modify growth rates of the young squirrels, and juvenile growth rate could be modified by natural selection. Natural selection should act to maximize the intrinsic rate of increase, and the sensitivity analysis presented in this paper provides an indication of the relative sensitivity of rate of increase to small changes in elements of the transition matrices. If increased growth of light animals can have a great effect on population growth rates, then the elements of the sensitivity matrices that corresponded to transitions of light animals to heavy mass classes should have been large relative to other elements in the matrix. This was indeed the case for the 
Uinta ground squirrels (Table 8), and may indicate that the potential exists for further increases in juvenile growth rate. Age-based sensitivities were largest for young animals, but the age-based results cannot provide the insights into growth and survival given by the mass-based analysis.

\section{Use of body mass in the analysis of mammalian population dynamics}

Estimation of the ages of small mammals has been a chronic problem for population biologists. Many methods have been proposed for age estimation: some of these methods (e.g., eye-lens mass) require sacrificing the animal. We have shown here and elsewhere that body mass, an easily acquired, nonstressful field measurement, can be an important demographic variable.

Body mass is also very variable, however, so to use body mass as a demographic character one must take care to ensure that body mass is measured under constant conditions for all animals. Many factors, including mass of recently ingested food, could introduce minor error in the measurement of body mass. In this study, we examined body mass only at emergence in spring, when females were at their minimum yearly body mass. Errors in mass estimation caused by trapping stresses are unavoidable, but can be minimized by careful monitoring of trapping techniques.

Small sample sizes are the bane of all ecological studies, but are even more crucial in studies of body-mass dynamics. Age-based studies only estimate one survival parameter for each age class, but mass-based studies have to estimate all transitions from one mass class to all other mass classes. For example, an agebased study using $n$ age classes has $n-1$ survival probabilities to estimate; a mass-based study with $n$ mass classes has $n^{2}$ parameters to estimate. Many of the between-mass class transition probabilities are so small that they can be set equal to 0.0 (i.e., transitions from mass class 5 to mass class 3 in this study), but there are still a substantial number of parameters to estimate.

Law (1983) discussed a method for examining population dynamics based on both body size and age that allows examination of body mass within age classes. Unfortunately, this method is difficult to apply to mammals because it requires estimation of a large number of parameters. In any case, this matrix (the Goodman matrix) provides results similar to a Lefkovitch matrix if the population dynamics are strongly size-based (Law 1983), as we have shown to be the case with Uinta ground squirrels. More importantly, one of the major conclusions that we wish to draw from our results is that one need not know ages of the animals in the population to examine the population dynamics.

Counteracting this need for larger sample sizes in the mass-based case is the ease with which body-mass ob- servations are collected. Known-age animals in a population have to be monitored over a series of years, but all mass classes can be estimated in 2 yr of study. Thus it seems that mass-based studies may be equally advantageous for long-lived and relatively short-lived species. If body mass gives as much information as age on survival and fecundity, use of body mass as the demographic categorical variable could be a valid and efficient way of analyzing population dynamics.

\section{ACKNOWLEDGMENTS}

We thank the many participants in the ground squirrel study who helped trap and observe the squirrels. The ground squirrel fieldwork was supported by National Institutes of Health Grant GM 11185 to D. F. Balph and A. W. Stokes and National Science Foundation Grants GB 5570, GB 8156, and GB 27215. We were supported by University of Kansas General Research Fund Grants to N. A. Slade and a Graduate Honors Fellowship to J. R. Sauer. We thank R. D. Holt, R. S. Hoffmann, and D. F. Balph for comments on the manuscript.

\section{LITERATURE CITED}

Armitage, K. B. 1981. Sociality as a life-history tactic of ground squirrels. Oecologia (Berlin) 49:36-49.,

Balph, D. F. 1984. Spatial and social behavior in a population of Uinta ground squirrels: interrelations with climate and annual cycle. Pages 326-352 in J. O. Murie and G. R. Michener, editors. The biology of ground-dwelling squirrels. University of Nebraska Press, Lincoln, Nebraska, USA.

Balph, D. F., and A. W. Stokes. 1963. On the ethology of a population of Uinta ground squirrels. American Midland Naturalist 69:106-126.

Caswell, H. 1978. A general formula for the sensitivity of population growth rate to changes in life history parameters. Theoretical Population Biology 14:215-230.

Clark, T. W. 1970. Early growth, development, and behavior of the Richardson ground squirrel (Spermophilus richardsoni elegans). American Midland Naturalist 83:197-205.

Dixon, W. J., editor. 1983. BMDP statistical software. 1983 revised printing. University of California Press, Berkeley, California, USA.

Falconer, D. S. 1981. Introduction to quantitative genetics. Second edition. Longman Press, London, England.

Holekamp, K. E. 1984. Dispersal in ground-dwelling sciurids. Pages 295-320 in J. O. Murie and G. R. Michener, editors. The biology of ground-dwelling squirrels. University of Nebraska Press, Lincoln, Nebraska, USA.

Kirkpatrick, M. 1984. Demographic models based on size, not age, for organisms with indeterminate growth. Ecology 65:1874-1884.

Law, R. 1983. A model for the dynamics of a plant population containing individuals classified by age and size. Ecology 64:224-230.

Lefkovitch, L. P. 1965. The study of population growth in organisms grouped by stages. Biometrics 21:1-18.

Leslie, P. H. 1945. The use of matrices in certain population mathematics. Biometrika 33:183-212.

Levenson, H. 1979. Sciurid growth rates: some corrections and additions. Journal of Mammalogy 60:232-235.

McLean, I. G. 1984. Spacing behavior and aggression in female ground squirrels. Pages 321-335 in J. O. Murie and G. R. Michener, editors. The biology of ground-dwelling squirrels. University of Nebraska Press, Lincoln, Nebraska, USA.

Michener, G. R. 1984a. Sexual differences in body weight patterns of Richardson's ground squirrels during the breeding season. Journal of Mammalogy 65:59-66. 
1984b. Age, sex, and species differences in the annual cycles of ground-dwelling sciurids: implications for sociality. Pages 79-107 in J. O. Murie and G. R. Michener, editors. The biology of ground-dwelling squirrels. University of Nebraska Press, Lincoln, Nebraska, USA.

Michener, G. R., and D. R. Michener. 1977. Population structure and dispersal in Richardson's ground squirrels. Ecology 58:359-368.

Murie, J. O., and D. A. Boag. 1984. The relationship of body weight to overwinter survival in Columbian ground squirrels. Journal of Mammalogy 65:688-690.

Myers, P., and L. L. Master. 1983. Reproduction by Peromyscus maniculatus: size and compromise. Journal of Mammalogy 64:1-18.

Neal, B. J. 1965. Growth and development of the roundtailed and Harris antelope ground squirrels. American Midland Naturalist 73:479-489.

Sauer, J. R., and N. A. Slade. 1985. Mass-based demography of a hispid cotton rat (Sigmodon hispidus) population. Journal of Mammalogy 66:316-328.

Sauer, J. R., and N. A. Slade. 1986a. Field-determined growth rates of prairie voles (Microtus ochrogaster): observed patterns and environmental influences. Journal of Mammalogy 67:61-68.

Sauer, J. R., and N. A. Slade. 1986b. Size-dependent population dynamics of Microtus ochrogaster. American Naturalist 127:902-908.

Shaw, W. T. 1926. Age of the animal and slope of the ground surface, factors modifying the structure of hibernation dens of ground squirrels. Journal of Mammalogy 7:91-96.

Sherman, P. W., and M. L. Morton. 1984. Demography of Belding's ground squirrels. Ecology 65:1617-1628.

Slade, N. A., and D. F. Balph. 1974. Population ecology of Uinta ground squirrels. Ecology 55:989-1003.

Slade, N. A., J. R. Sauer, and G. E. Glass. 1984. Seasonal variation in field-determined growth rates of the hispid cotton rat (Sigmodon hispidus). Journal of Mammalogy 65: 263-270.

Werner, P. A., and H. Caswell. 1977. Population growth rates and age versus stage-distribution models for teasel (Dipsacus sylvestris Huds.). Ecology 58:1103 1111. 